\title{
Structural modification of indium implanted glassy carbon by thermal annealing and SHI irradiation
}

\author{
E.G. Njoroge ${ }^{* 1,2}$, L.D. Sebitla ${ }^{1,3}$, C.C. Theron ${ }^{1}$, M. Mlambo ${ }^{1}$, T.T.Hlatshwayo ${ }^{1}$, O.S. Odutemowo ${ }^{1}$, \\ V.A. Skuratov ${ }^{4,5}$, E. Wendler ${ }^{6}$, J.B. Malherbe ${ }^{1}$ \\ ${ }^{1}$ Physics Department, University of Pretoria, Pretoria, South Africa. \\ ${ }^{2}$ ENGAGE, University of Pretoria, Pretoria, South Africa \\ ${ }^{3}$ Physics Department, University of Botswana, Gaborone, Botswana. \\ ${ }^{4}$ National Research Nuclear University MEPhI, Moscow, Russia. \\ ${ }^{5}$ Dubna State University, Dubna, Russia. \\ ${ }^{6}$ Institut für Festkörperphysik, Friedrich-Schiller-Universität Jena, Germany.
}

\begin{abstract}
The structural changes, migration behaviour of indium (In) implanted into glassy carbon (GC) and the effect of annealing on radiation damage introduced by ion implantation have been investigated. The GC substrates were implanted with $360 \mathrm{keV}$ indium ions to a fluence of $2.0 \times 10^{16}$ ions $/ \mathrm{cm}^{2}$ at room temperature (RT) and $350{ }^{\circ} \mathrm{C}$. The RT implanted samples were isochronally annealed in vacuum between 200 and $1000{ }^{\circ} \mathrm{C}$ for 1 hour. The $350{ }^{\circ} \mathrm{C}$ implanted GC substrates were irradiated $167 \mathrm{MeV}$ with $\mathrm{Xe}^{26+}$ ions at room temperature to a maximum fluence of $5.0 \times 10^{14} \mathrm{ions} / \mathrm{cm}^{2}$. The implanted GC structure was damaged and had an almost amorphized structure. Annealing of the RT implanted samples resulted in some recrystallization which increased with temperature and the diffusion behaviour of implanted In. Fickian diffusion of implanted In started after annealing at $300{ }^{\circ} \mathrm{C}$, however, structural changes in the $\mathrm{GC}$ were observed after annealing at $200{ }^{\circ} \mathrm{C}$. Annealing at 400 and $600{ }^{\circ} \mathrm{C}$ resulted in the diffusion of In toward the surface of GC accompanied by a loss of In. The SHI irradiation of the $350{ }^{\circ} \mathrm{C}$ implanted samples at increasing fluence, did not result in a detectable migration of implanted In.
\end{abstract}

\section{Keywords:}

Glassy carbon, indium, RBS, Ion Implantation, Diffusion, Raman

* Corresponding author. Tel.: +27 12 4202668; E-mail address: eric.njoroge@up.ac.za 


\section{Introduction}

Carbon can exist in pure form as graphite, diamond and amorphous carbon or produced synthetically as glassy carbon, fullerenes and carbon nanotubes. Glassy carbon (GC) or vitreous carbon is a synthetic form of carbon with very attractive physical and chemical characteristics which combine ceramic properties with those of graphite. GC is a homogenous isotropic and continuous form of carbon material prepared by controlled pyrolysis of organic resin precursors [1]. This black and glass-like material has fracture behaviour is similar to that of glass [2]. GC has a complicated network structure having a level microstructural disorder consisting of a mixture of graphite like ribbons or micro fibrils (turbostratic structure) therefore long range order does not exist [3]. GC is a micro-polycrystalline material made up of multilayers primarily consisting of $\mathrm{sp}^{2}$ bonds [4] but unlike graphite it has been suggested that GC has a fullerene-related microstructure $[5,6]$. This implies that GC has graphitic ordering between that of HOPG and amorphous carbon.

GC exhibits attractive physical, chemical and mechanical properties which make the material have very promising technological applications. These include moderate hardness, resistance to corrosion and wear (at RT and high temperatures), high chemical inertness [3], impermeability to gases and liquids [7], high temperature stability (does not transform to graphite even at $3000{ }^{\circ} \mathrm{C}$ ) [8], high thermal conductivity [9], good resistance to thermal shock and low coefficient of thermal expansion. GC has a relatively lower density $\left(1.4-1.5 \mathrm{~g} / \mathrm{cm}^{3}\right)$ compared with graphite $\left(2.3 \mathrm{~g} / \mathrm{cm}^{3}\right)$ or diamond $\left(3.52 \mathrm{~g} / \mathrm{cm}^{3}\right)$ [10]. This low density suggests the existence of voids or a porous microstructure but these voids are not connected and this is the reason GC is impervious to gases $[2,10]$. Despite the low density, glassy carbon has high mechanical strength and elastic moduli, which exceed those of other graphitic materials and also exhibits elastic behaviour till fracture [11]. GC has many useful industrial applications such as vacuum evaporation sources, containment of fission products (FPs), zone-refinement crucibles and encapsulation of nuclear fuel elements [8,9]. This material has been proposed as a protective layer on the graphite reactor core surface and as a candidate material for cooling pipes in molten salt reactor nuclear power plants [12]. Indium (In) is a heavy element which has a low melting point $\left(156{ }^{\circ} \mathrm{C}\right)$, reasonably good electrical and thermal conductivity. In has a high neutron capture cross section for thermal neutrons (190 barns) therefore making it a material that has promising applications such as in control rods and components in nuclear reactors [13].

Ion implantation can be used to introduce ions into a substrate in a reproducible manner by controlling the depth and concentration of implanted atoms. Ion implantation can modify the chemical and physical properties of a material by introducing defects along the collision cascades through the rapid dissipation of energy by the incident ions in the near surface regions of a material [14,15]. Implantation by ions such as Indium can induce damage or disorder of the near surface structure due to its heavy mass even at relatively low doses through energy deposition by elastic and inelastic collisions. On the contrary, ion implantation can also introduce beneficial effects such as improve wear resistance, increase in atomic density [16] and increase the thermal conductivity of glassy carbon [11]. These changes in material properties are due to structural modifications of the near surface region of GC by amorphization due to compaction of the implanted region. Amorphization of GC has been reported to be independent of the implanted ion species and therefore not due to chemical effects $[14,15,17]$.

Since ion implantation has been shown to enhance the mechanical properties of GC, the aim of this study is to improve the performance of GC that is proposed as a containment material for high level nuclear waste (HLW) and shielding material in nuclear reactors. Implantation with Indium can induce 
an increase in density and thermal conductivity of GC while at the same time enhance the neutron capture cross section properties of the substrate for nuclear applications. We look into the possibility of using In implanted GC as an encapsulation or containment material for FPs with increased neutron absorption properties which can adjust neutron flux and reduce radiation damage to GC.

For GC to be a good candidate for containment, it must be a good diffusion barrier for fission products and its near-surface region structure must remain unchanged so that it retains its properties after In implantation, annealing and even after swift heavy ion (SHI) irradiation. Previous work on ion species implanted in GC include Be [18], Cs [19], Sr [20], Co [4] K [21], Na [15], Ti [22], N [23], W [17], Cd [24] but after extensive literature research no study of In implanted in GC has been carried out and no study on SHI irradiation of implanted GC has been previously conducted. The diffusion coefficient calculated in this study after isochronal annealing has been compared to that of beryllium implanted into GC calculated by Koskelo et al [18].

In this study, the effectiveness of glassy carbon as a good containment material, In ions are implanted into GC substrates to a fluence of $2.0 \times 10^{16}$ ions $/ \mathrm{cm}^{2}$ at room temperature and at $350{ }^{\circ} \mathrm{C}$. Post ion implantation annealing and SHI irradiation experiments of implanted GC were conducted to investigate the stability, diffusion and structural modification of GC. This has been performed by Raman spectroscopy and Rutherford backscattering spectrometry (RBS) analysis techniques.

\section{Experimental}

Commercially available Glassy carbon (SIGRADUR ${ }^{\circledR} \mathrm{G}$ ) with density of $1.42 \mathrm{~g} / \mathrm{cm}^{3}$ was used as the substrate. The GC substrates were mechanically polished to a mirror finish with a $1 \mu \mathrm{m}$ diamond solution. Indium ions with energy of $360 \mathrm{keV}$ were implanted into the polished GC to a fluence of $2.0 \times 10^{16}$ ions $/ \mathrm{cm}^{2}$ at room temperature (RT) and at $350{ }^{\circ} \mathrm{C}$. The In implantation dose was chosen to ensure that the indium profile would be measurable by RBS and above the detection limits of this technique. Some of the RT implanted samples were isochronally annealed in vacuum at temperatures of $200,300,400,600$ and $1000^{\circ} \mathrm{C}$ for 1 hour. The samples implanted at $350{ }^{\circ} \mathrm{C}$ were irradiated with $\mathrm{Xe}^{26+}$ ions $(167 \mathrm{MeV})$ at room temperature to a fluence of $5.0 \times 10^{12}, 5.0 \times 10^{13}, 1.0 \times 10^{14}$, and $5.0 \times 10^{14}$ ions $/ \mathrm{cm}^{2}$ using the IC-100 cyclotron at FLNR JINR in Dubna, Russia.

The structure of GC before implantation, after implantation, the effect of annealing and SHI irradiation were investigated by Raman spectroscopy. The Raman spectra were recorded with a T64000 series II triple spectrometer system from HORIBA scientific, Jobin Yvon Technology. The Raman spectra were obtained using $514.5 \mathrm{~nm}$ argon laser, through an Olympus microscope with a 50x objective lens and laser power of $1.5 \mathrm{~mW}$. The depth profiles of the as-implanted indium, after annealing and SHI irradiation were monitored using Rutherford backscattering spectrometry (RBS) using $\alpha$-particles with energy of $1.6 \mathrm{MeV}$ at a backscattering angle of $165^{\circ}$. The beam current maintained between 10 and 15 $\mathrm{nA}$ during the measurements with a $1 \mathrm{~mm}$ beam spot. The charge collected was approximately $8 \mu \mathrm{C}$ with a detector resolution of $12 \mathrm{keV}$.

\section{Results and Discussion}

\subsection{Thermal Annealing}

In this study, $360 \mathrm{keV}$ In ions were implanted into GC at room temperature and from SRIM calculations nuclear energy loss process is expected to dominate. This process which involves elastic collisions results in the transfer of energy and momentum from the incoming ions to the GC substrate which leads to displacement of the target atoms, change in structure.

Raman spectroscopy was used investigate the structure of GC before and after implanting with In ions to evaluate the structural modification after annealing and SHI irradiation. The Raman spectra of 
pristine $\mathrm{GC}$, room temperature and $350{ }^{\circ} \mathrm{C}$ implanted GC in the $1200-1800 \mathrm{~cm}^{-1}$ range are shown in Figure 1. The pristine GC spectrum is composed two typical peaks at approximately 1350 and $1585 \mathrm{~cm}^{-}$ 1. The peak at approximately $1350 \mathrm{~cm}^{-1}$ corresponds to a long-range disorder mode of graphite structure (D peak) while the peak at $1585 \mathrm{~cm}^{-1}$ (G peak) is attributed to the microcrystalline graphite structure [25]. The two peaks are characteristic of carbon materials with $\mathrm{sp}^{2}$ bonds and describe the orderdisorder relationship in the material [6]. There is also a hump at $1620 \mathrm{~cm}^{-1}$ (D' peak) which is attributed to small sp $\mathrm{sp}^{2}$ crystallites in GC that results in a Raman doublet of the 1585 and $1620 \mathrm{~cm}^{-1}$ peaks.

For the RT and $350{ }^{\circ} \mathrm{C}$ implanted $\mathrm{GC}$, the effect of In implantation on the structure of GC is revealed by the drastic change in the Raman spectra with the appearance of a broad peak between 1200 and 1700 $\mathrm{cm}^{-1}$. This broad peak is due to merging of the $\mathrm{D}$ and $\mathrm{G}$ peaks into a single wide peak after In implantation. The indium ion implantation damaged the near surface region of GC resulting in an increase in disorder and the destruction of the graphitic microcrystals. The shape of the broad peak is similar to that of disordered carbon structure. Although GC is not a crystalline material, its structure consists of graphitic microcrystallites within the turbostratic structure which lack long range order. This increase in disordering of the $\mathrm{sp}^{2}$ graphitic units and reduction of crystallite size due to ion implantation has been referred to as "amorphization" of GC by other authors [17].

The implantation at $350{ }^{\circ} \mathrm{C}$ had similar effect on the structure of $\mathrm{GC}$ compared to the RT implantation and the shape of the broad peaks are almost the identical. This change into an amorphous structure has been reported to improve the wear resistance of GC and is due to the $\mathrm{sp}^{2}$ to $\mathrm{sp}^{3}$ bond conversion within the damaged region [26]. Previous work on HRTEM analysis of pristine and ion bombarded GC has shown that the substrate structure was transformed from fullerene-like to mostly amorphous-like structure [27]. The large amount of ion implantation induced damage is expected to affect the indium diffusion during subsequent thermal anneal processes. This broad band has been observed in glassy carbon implanted with $320 \mathrm{keV} \mathrm{Xe} \mathrm{ions} \mathrm{[14],} 360 \mathrm{KeV} \mathrm{Cd}$ ions [24] and $200 \mathrm{keV} \mathrm{Sr}$ ions [28] at room temperature and fluences of $10^{14}-10^{16}$ ions $/ \mathrm{cm}^{2}$.

Figure 1, 2 and 7 show the Raman spectra fitted using the Breit-Wigner-Fano (BWF) + Lorentzian lines combination, and good fits were obtained indicating that the combination was appropriate for analysing the $\mathrm{G}$ and $\mathrm{D}$ bands. By fitting the Raman spectra, it is possible to reliably extract information on the peak positions and intensities. The Raman spectra of pristine GC, RT and $350{ }^{\circ} \mathrm{C}$ implantations were fitted using an asymmetric BWF line for the G and D' peaks and a Lorentzian for the D peak. The intensity ratio of the $\mathrm{D}$ and $\mathrm{G}$ peaks gives a quantitative measure of average crystallite size. The $I_{\mathrm{D}} / I_{\mathrm{G}}$ ratio of pristine GC was found to be 1.4 and this value is typical for nano-sized disordered $\mathrm{sp}^{2}$ carbon materials [8]. The Tuinstra-Koenig relation [29] can be used to estimate the average in-plane crystalline size $L_{a}$ of the pristine glassy carbon and it is given as:

$$
\frac{I_{D}}{I_{G}}=\frac{C_{\lambda}}{L_{a}}
$$

where $C_{\lambda}$ is a laser wavelength dependent constant taken as $44 \AA$ for $514.5 \mathrm{~nm}$ excitation laser. This relationship holds for $\mathrm{sp}^{2}$ bonded carbon materials with large crystallite size in range of $2.5 \mathrm{~nm}<L_{a}<$ $300 \mathrm{~nm}$. The crystallite size, $L_{a}$ for SIGRADUR ${ }^{\circledR}$ G GC was calculated using equation 1 and found to be $3.1 \mathrm{~nm}$. This crystallite size confirms that glassy carbon is indeed a nano-crystalline carbon material.

The $I_{\mathrm{D}} / I_{\mathrm{G}}$ ratio after RT implantation was found to have reduced as expected from the pristine value to 0.97. For small cluster size, $L_{a}$ can be calculated using

$$
\frac{I_{D}}{I_{G}}=C^{\prime}(\lambda) L_{a}^{2}
$$


where the constant $C^{\prime}(\lambda)$ is $0.0055 \AA^{-2}$ [30]. The crystallite size of the damaged region after ion implantation was found to be $1.3 \mathrm{~nm}$. This confirms that In ion implantation leads to more damage and a highly disordered region which has a reduced crystallite size.

After ion implantation, the D peak position shifted from $1350 \mathrm{~cm}^{-1}$ to $1366 \mathrm{~cm}^{-1}$ while the G peak moved to a lower wavenumber from $1585 \mathrm{~cm}^{-1}$ to $1573 \mathrm{~cm}^{-1}$. The reduction of the peak ratio together with the downshift of the $\mathrm{G}$ peak after implantation reflects an increase in the amount of disorder and an increase in the $\mathrm{sp}^{3}$ content and/or bond-angle distortion associated with an increase in the number of tetrahedral bonds forming due to implantation [6]. The G peak down shift by $12 \mathrm{~cm}^{-1}$ indicates that the degree of disorder within the implanted region of GC was not that severe and did not get to amorphous carbon level observed after $320 \mathrm{keV}$ Xe ions implantation at fluences $6 \times 10^{16} \mathrm{ions} / \mathrm{cm}^{2}$ [14].

Raman spectroscopy analysis of GC is highly sensitive to structural changes in the region between the surface and the projected range of implanted ions [24,28]. The origin of the Raman signal is expected to be limited to the implanted region of GC. This was confirmed by calculating the penetration depth of the Raman laser with wavelength of $514.5 \mathrm{~nm}$ and we obtained $90 \mathrm{~nm}$ [31]. The penetration depth is well within the implantation damaged region which was found to be wider after RBS analysis. Therefore, the thickness of the implanted layer is wide enough to reduce the substrate effect. The results discussed in Figures 1,2 and 7 correspond to Raman signals obtained from the surface up a depth of about $90 \mathrm{~nm}$.

The effect of annealing on the structure of the RT In implanted GC is shown in Figure 2 and the BWF + Lorentzian line fit combination has been included. The broad spectrum of the as-implanted sample changed after annealing at $200{ }^{\circ} \mathrm{C}$, where the $\mathrm{G}$ peak intensity was observed to increase. The Raman spectra of samples annealed at 300 and $400{ }^{\circ} \mathrm{C}$ are similar to that annealed at $200{ }^{\circ} \mathrm{C}$ with a slight increase in $\mathrm{G}$ peak intensity with increase in annealing temperature.

When the annealing temperature was increased to $600{ }^{\circ} \mathrm{C}$, further changes in the Raman spectrum can be observed. At this temperature, two peaks become distinguishable near the $\mathrm{D}$ and $\mathrm{G}$ peak positions of the pristine glassy carbon. This change in the Raman spectrum is ascribed to changes in the GC structure and therefore this temperature can be considered as the dynamic radiation damage annealing temperature when the damaged layer slightly recrystallizes.

The effect of high temperature annealing on the structure of In implanted glassy carbon was investigated by annealing at $1000{ }^{\circ} \mathrm{C}$. The intensity of the $\mathrm{D}$ and $\mathrm{G}$ peaks increased as seen in Figure 2. This is suggestive of some micro-recrystallization processes within the damaged near surface region of GC was taking place. An upshift of $\mathrm{G}$ band after annealing at 600 and $1000{ }^{\circ} \mathrm{C}$ was observed to occur which is due to increase in ordering and the graphite microcrystallites within the damaged region which grew in size and quantity [32]. This indicates that some form of recovery process occurred within the implanted region due to the heat treatment. The $\mathrm{G}$ and $\mathrm{D}$ peak positions did not return to the original positions neither did the $I_{\mathrm{D}} / I_{\mathrm{G}}$ ratio at highest annealing temperature of $1000{ }^{\circ} \mathrm{C}$. This implies that the recovery process within the implanted region did not revert to pristine GC structure and some damage introduced by implantation was still retained in the glassy carbon structure after annealing.

The depth distribution of indium implanted in GC and the diffusion behaviour of indium after annealing was investigated by RBS analysis technique. Figure 3 shows the depth distribution of indium ions after RT implantation derived from RBS measurements along with the theoretical distribution and the damage profile calculated using the SRIM-2013 code [33].

Analysis of the experimental depth profile of the implanted In was found to be Gaussian and the FWHM was found to be slightly broader than the simulated SRIM profile. This difference in FWHM resulted 
in a higher SRIM simulation peak intensity at the projected range. The In projected range $\left(R_{p}\right)$ and range straggling $\left(\Delta \mathrm{R}_{\mathrm{p}}\right)$ of the of 360-keV In distribution in GC calculated with SRIM were approximately 145 $\mathrm{nm}$ and $30 \mathrm{~nm}$, respectively. The projected range $\left(\mathrm{R}_{\mathrm{p}}\right)$ calculated by the SRIM was comparable with the experimental value but the straggling $\left(\Delta \mathrm{R}_{\mathrm{p}}\right)$ was lower. The range straggling of the experimental profile is about 23\% larger than predicted. Therefore, the In peak is below its surface channel position and the width of the radiation damaged GC region observed in Raman results is limited to about $260 \mathrm{~nm}$ from the surface.

The number of vacancies produced as a result of the implantation of In in glassy carbon is also shown in Figure 3. The maximum damage level of $22 \mathrm{dpa}$ is higher than the reported required critical value to amorphize GC of about $0.2 \mathrm{dpa}$ [32]. The damage profile has a maximum at $90 \mathrm{~nm}$ which is closer to the surface compared to the implanted In distribution and simulated profiles. The concentration of the damage towards the surface of the glassy carbon indicates that a large number of carbon atoms were displaced near the surface of the glassy carbon and that the diffusion of In due to annealing should be towards the surface.

Figure 4 shows the RBS spectrum of the sample implanted at $350{ }^{\circ} \mathrm{C}$ which has a broad distribution that is wider than the RT implanted one. The indium ions are distributed deeper into the GC substrate $(>200 \mathrm{~nm})$ and also towards the surface. The arrow in Figure 4 indicates the In surface channel position and it can be seen that the In high energy edge is at the In surface position indicating that the implanted In ions appeared at the surface of GC. These observations imply that In implantation at $350{ }^{\circ} \mathrm{C}$ induced some diffusion during implantation due to temperature and radiation damage.

Figure 5 shows the depth profiles obtained from the RBS spectra of RT In implanted GC before and after isochronal annealing between 200 and $600{ }^{\circ} \mathrm{C}$ for 1 hour. The sample annealed at $200{ }^{\circ} \mathrm{C}$ showed no noticeable change in the In peak the indium depth profile remained the same compared to the asimplanted profile. This indicates that this temperature was too low to cause any significant change in the indium distribution, i.e. to cause any diffusion of indium at this temperature. Although no change was observed from RBS analysis after annealing at $200^{\circ} \mathrm{C}$, Raman results do indicate that the structure of the damaged region had changed after annealing at this temperature.

At annealing temperature of $300{ }^{\circ} \mathrm{C}$, the depth profile broadened and exhibited tailing on both sides of the profile. The FWHM of this profile is wider than that of the as-implanted and $200{ }^{\circ} \mathrm{C}$ profiles as seen in Figure 5 implying that the implanted indium starts to diffuse at $300{ }^{\circ} \mathrm{C}$. The shape of the profile is still Gaussian, the projected range moved slightly into the bulk to $154 \mathrm{~nm}$ and the implanted indium diffused toward the surface and into the bulk of GC. Since the depth profile was still Gaussian, this indicates that Fickian diffusion occurred when the samples were annealed at this temperature. No indium was lost and the integral count of In ions remained the same as that of as-implanted as seen in Figure 6. The diffusion of In towards the bulk is within the less damaged region and not the pristine GC substrate. This broadening of the profile is due to indium trapping induced by defects within the damaged region.

After annealing at $400{ }^{\circ} \mathrm{C}$, the shape of the indium profile changes with further broadening occurring. The profile is asymmetric, that is, no longer Gaussian and the In profile shifted towards the surface due to the thermal diffusion of In. A smaller fraction of indium ions diffused into the bulk, while at the same time, some of the implanted indium ions migrated toward the surface of GC. Once the diffused indium reached the surface of $\mathrm{GC}$ at a temperature of $400{ }^{\circ} \mathrm{C}$, the retained ratio can be seen to have decreased slightly by about $2 \%$ due to evaporation from the surface as seen in Figure 5 and 6 . This diffusion towards the surface is in the more damaged region of GC. No significant shift towards the region of 
undamaged GC beyond the damaged region was observed to occur indicating a presence of a diffusion boundary and diffusion occurred in radiation damaged region.

From Figure 5 and Figure 6 it is evident that indium was being lost from the surface of the GC substrate after annealing at $600{ }^{\circ} \mathrm{C}$, however, further diffusion into the undamaged bulk seems to be negligible. The amount of retained indium after annealing at $600{ }^{\circ} \mathrm{C}$ is about $48 \%$ and this is due to the evaporation from the GC surface of the In that has diffused from the implanted region toward the GC surface. We speculate that some form of recovery process has taken place in the less damaged region of the GC at the end of range.

The diffusion of In between $300{ }^{\circ} \mathrm{C}$ and $600{ }^{\circ} \mathrm{C}$ is due to the presence of defect traps present in the damaged region. At this temperature range, the thermal energy of implanted ions is enough overcome the diffusion barriers in the system and migrate through the damaged region of glassy carbon towards the surface. Significant loss of indium was observed to occur at $1000{ }^{\circ} \mathrm{C}$ and no indium was retained at this temperature. Although all the indium was lost after annealing at $1000{ }^{\circ} \mathrm{C}$, the structure of the near surface region of GC did not revert to the pristine GC structure as observed in the Raman spectrum for this sample. Typically a $260 \mathrm{~nm}$ wide radiation damaged region remains after annealing at $1000{ }^{\circ} \mathrm{C}$.

The diffusion coefficient of indium migration within the damaged glassy carbon was estimated by comparing the FWHM of the as-implanted indium depth profile to that of the sample annealed at 300 ${ }^{\circ} \mathrm{C}$ for 1 hour using an in-house code developed by Malherbe et al [34]. The value for the diffusion coefficient of $2.15 \times 10^{-17} \mathrm{~m}^{2} \mathrm{~s}^{-1}$ was obtained. The diffusion coefficient of beryllium in GC at 1285 and $1340{ }^{\circ} \mathrm{C}$ has been reported as $3.0 \times 10^{-17}$ and $2.5 \times 10^{-17} \mathrm{~m}^{2} \mathrm{~s}^{-1}$ respectively by Koskelo et al [18]. Although the temperatures are much higher, the diffusion coefficients are comparable and within the same magnitude indicating similar diffusion mechanisms (Fickian diffusion).

\subsection{SHI Irradiation}

The fission process in nuclear reactors involves the release nuclides with energy in the order of 100 $\mathrm{MeV}$, that is, the energy range of swift heavy ions (SHIs). Since GC is used in nuclear reactors and encapsulation of high level nuclear waste (HLW), it will be subjected to bombardment by FPs of different energies including the SHIs energy range. Irradiation of GC can lead to structural changes depending on the energy, fluence of irradiating species and the temperature of the substrate. These changes occur when high energy particles are slowed down in the material due to loss of energy via elastic and inelastic collisions. This was the motivation to investigate the retention of implanted ions within the radiation damaged GC region and structural modifications of the GC substrates after SHI irradiation. Using SRIM code, the energy loss due to of $167 \mathrm{MeV}$ Xe ions in GC and indium was found to be via electronic excitation from inelastic collisions and not nuclear elastic collisions.

The Raman spectra of SHI irradiated GC are compared with the $350{ }^{\circ} \mathrm{C}$ implanted spectrum in Figure 7. The Raman spectra have been fitted using the BWF + Lorentzian lines combination. No frequency shift for the D band or the G band was observed even at the highest SHI irradiation fluence of $5 \times 10^{14}$ ions $/ \mathrm{cm}^{2}$. After SHI irradiation at a fluence of $5 \times 10^{12}$ ions $/ \mathrm{cm}^{2}$ the $\mathrm{G}$ peak became slightly more prominent compared to the $\mathrm{D}$ peak height. The intensity of the $\mathrm{D}$ peak was observed to decrease after further SHIs irradiation to the highest fluence. This revealed that some disorder remained in the near surface GC after SHI irradiation and the degree of disorder increased with increasing fluence of irradiation. With increase in the irradiation fluence, the damage level also increased and the clusters become smaller due to loss of short-range order. The thermal spike due to SHIs irradiation is not sufficient enough to cause further damage or recrystallization of the implantation damaged region. 
The RBS spectra of GC irradiated with SHIs to different fluence from $5 \times 10^{12}$ to $5 \times 10^{14}$ ions $/ \mathrm{cm}^{2}$ are shown in Figure 8. It was observed that the RBS profiles did not change with increase in irradiation fluence and no detectable diffusion of indium implanted in GC occurred. The defects introduced in the GC structure at $350{ }^{\circ} \mathrm{C}$ indium implantation, are still present after SHI irradiation and therefore SHI irradiation does not influence the diffusion of indium. No diffusion towards the bulk was expected since the annealed samples did indicate that no diffusion of indium towards un-damaged GC occurred and the implanted indium was stable.

\section{Discussion}

Based on Raman results, the near surface region of GC implanted with In ions was transformed into an highly disordered layer by RT implantation of $360 \mathrm{keV}$ In ions to a fluence of $2 \times 10^{16} \mathrm{ions} / \mathrm{cm}^{2}$. The density of this region is expected to have increased, while that of the bulk GC substrate beyond the ion range remained similar to that of pristine GC $\left(1.42 \mathrm{~g} / \mathrm{cm}^{3}\right)$. The increase in density is due to physical compaction of the near surface region of GC, leading to a reduction in the number of pores and increased impermeability.

The implanted indium is distributed within the damaged region which extends from the surface up to a depth of $260 \mathrm{~nm}$. The implanted In only diffused during annealing towards the surface from the damaged glassy carbon region and did not diffuse into undamaged bulk GC. This indicates that In diffusion is a radiation damage enhanced mechanism, since it diffused within in the defective region towards the surface. Since In has a larger atomic radius compared to the $\mathrm{C}$ atom, this can lead to significant strain in the implanted region of the glassy carbon, leading to the outwards diffusion of the In from the damaged region of glassy carbon. The diffusion of In towards the bulk is in the less damaged region and not the damage-free/pristine GC.

Implantation of In in GC produces lots of vacancies, and the subsequent annealing of the damaged region led to some recrystallization. Although no change was observed from RBS analysis after annealing at $200{ }^{\circ} \mathrm{C}$, Raman results indicate that the structure of the implantation damaged region had changed after annealing at this temperature. The $I_{\mathrm{D}} / I_{\mathrm{G}}$ ratio after annealing at $200{ }^{\circ} \mathrm{C}$ increased slightly compared to the as implanted sample indicating some recrystallization and increase in crystallite size according to equation (2). It must be stated that this recrystallization occurred when no diffusion of In was observed to occur due to trapping of implanted In within the damaged GC layer.

Raman and RBS results show that there was some structural modification of the radiation damaged region after annealing influenced by the diffusion process. Decrease in the $I_{\mathrm{D}} / I_{\mathrm{G}}$ ratio was observed from 300 to $600{ }^{\circ} \mathrm{C}$ which suggests a gradual decrease in crystallite size. At this temperatures, In was observed to diffuse towards the surface and out of the GC substrate. The diffusing In breaks down the surrounding crystallites leading to a detrapping mechanism to enable them to diffuse and in the process reduce the crystallite sizes. Once all the implanted In had diffused out of the $\mathrm{GC}$ at $1000{ }^{\circ} \mathrm{C}$, an increase in the $\mathrm{I}_{\mathrm{D}} / \mathrm{I}_{\mathrm{G}}$ ratio was observed. This led to an increase in graphitic order within the damaged layer. No evidence of indium carbide formation was observed, even after annealing at $1000{ }^{\circ} \mathrm{C}$ where no In was retained with the GC matrix.

Using the amorphization trajectory [30], the In ion implantation amorphized the near surface region of GC and converted about $10 \%$ of the $\mathrm{sp}^{2}$ bonds into $\mathrm{sp}^{3}$ bonds at these damage levels producing high density material. This conversation of the $\mathrm{sp}^{2}$ to diamond-like $\mathrm{sp}^{3}$ bonds is responsible for the reported high hardness and strength of the GC. Since the GC structure contains micro-pores which lead to mechanical weakness, the amorphization and densification of the near surface region of GC, should result in a high strength material which suppressing crack propagation and with a high neutron capture 
cross section. These results make In implanted GC a promising candidate for application as a radioactive containment material and as a component in nuclear reactors.

\section{Conclusions}

The GC near surface regions were transformed to highly disordered structure by indium $(360 \mathrm{KeV})$ ions implantation up to a fluence of $2 \times 10^{16} \mathrm{ions} / \mathrm{cm}^{2}$ at RT. Raman results revealed a significant decrease in the $\mathrm{I}_{\mathrm{D}} / \mathrm{I}_{\mathrm{G}}$ ratio after indium implantation predicting a strong disorder increase at the near surface region which became more dense but a true amorphous structure was not attained. From the depth profile of In implanted GC and the results of SRIM simulation, the thickness of the implantation damaged layer was approximately $260 \mathrm{~nm}$. The RT implanted In profiles are stable after annealing up to $300{ }^{\circ} \mathrm{C}$ where Fickian diffusion was observed to occur. At higher temperatures the In ions migrated toward the surface and out of the GC substrate. The implanted region slightly regained its original structure after annealing highest temperature of $1000{ }^{\circ} \mathrm{C}$ when all the implanted In had diffused out. The thermal spike due to SHI irradiation at increasing doses did not result in any In diffusion but only led to further damaging of the implanted region. The SHI irradiated GC resulted in further break down of the graphitic ribbons leading to increased degree of bond disorder within the damaged region resulting in smaller crystallite size but no diffusion of implanted indium was observed. Therefore, the indium implantation enhanced GC with increased neutron capture cross section is a promising candidate for radioactive material containment or use in nuclear reactors.

\section{Acknowledgements}

The financial support from the National Research Foundation (NRF) of South Africa is appreciated.

\section{References}

[1] A. Craievich, On the structure of glassy carbon, Mater. Res. Bull. II (1976) 1249-1256.

[2] N.L. Pocard, D.C. Alsmeyer, R.L. McCreery, T.X. Neenan, M.R. Callstrom, Doped glassy carbon: a new material for electrocatalysis, J. Mater. Chem. 2 (1992) 771.

[3] P.K. Chu, L. Li, Characterization of amorphous and nanocrystalline carbon films, Mater. Chem. Phys. 96 (2006) 253-277.

[4] V. Lavrentiev, J. Vacik, H. Naramoto, Structural phenomena in glassy carbon induced by cobalt ion implantation, Appl. Phys. A Mater. Sci. Process. 92 (2008) 673-680.

[5] P.J.F. Harris, Fullerene-related structure of commercial glassy carbons, Philos. Mag. 84 (2004) 3159-3167.

[6] H. Saitoh, T. Shinada, Y. Ohkawara, T. Shinada, Surface Modification of Glassy Carbon by Pulsed Laser Irradiation with Several Wavelengths, J. Appl. Phys. 41 (2002) 5359-5366.

[7] T. Noda, M. Inagaki, S. Yamada, A Comment on the Structure of Glassy Carbon, Bull. Chem. Soc. Jpn. 41 (1968) 3023-3024.

[8] S.S. Bukalov, L.A. Leites, A. Sorokin, A.S. Kotosonov, Structural Changes in Industrial Glassy Carbon As a Function of Heat Treatment Temperature According To Raman Spectroscopy and X-Ray, Nanosyst. Physics, Chem. Math. 5 (2014) 186-191. 
[9] E.A. Taft, H.R. Philipp, Optical Properties of Graphite, Phys. Rev. A. 138 (1965) 197-199.

[10] O.J.A. Schueller, S.T. Brittain, C. Marzolin, G.M. Whitesides, Fabrication and Characterization of Glassy Carbon MEMS, Chem. Mater. 9 (1997) 1399-1406.

[11] Y.S. Virgil'ev, I.G. Lebedev, Effect of neutron irradiation on properties of glassy carbon, Inorg. Mater. 38 (2002) 668-673.

[12] V. Bernardet, S. Gomes, S. Delpeux, M. Dubois, K. Guérin, D. Avignant, G. Renaudin, L. Duclaux, Protection of nuclear graphite toward fluoride molten salt by glassy carbon deposit, J. Nucl. Mater. 384 (2009) 292-302.

[13] A.M. Russell, K.L. Lee, Structure-Properties relations in nonferrous metals, John Wiley \& Sons, Inc, New Jersy, 2005.

[14] D.G. McCulloch, S. Prawer, A. Hoffman, Structural investigation of xenon-ion-beamirradiated glassy carbon, Phys. Rev. B. 50 (1994) 5905.

[15] M. Iwaki, K. Terashima, Change in atomic density of glassy carbon by Na ion implantation, Surf. Coatings Technol. 128-129 (2000) 429-433.

[16] A. V. Krasheninnikov, K. Nordlund, Ion and electron irradiation-induced effects in nanostructured materials, J. Appl. Phys. 107 (2010) 1-70.

[17] D. McCulloch, A. Hoffman, P.J. Evans, S. Prawer, Structural and chemical bonding investigation of tungsten implanted glassy carbon, Nucl. Inst. Methods Phys. Res. B. 80-81 (1993) 1460-1463.

[18] O. Koskelo, U. Köster, I. Riihimäki, J. Räisänen, Migration kinetics of ion-implanted beryllium in glassy carbon, Diam. Relat. Mater. 17 (2008) 1991-1993.

[19] D.F. Langa, N.G. Van Der Berg, E. Friedland, J.B. Malherbe, A.J. Botha, P. Chakraborty, E. Wendler, W. Wesch, Heat treatment of glassy carbon implanted with cesium at room and high temperatures, Nucl. Inst. Methods Phys. Res. B. 273 (2012) 68-71.

[20] O.S. Odutemowo, J.B. Malherbe, C.C. Theron, E.G. Njoroge, E. Wendler, In-situ RBS studies of strontium implanted glassy carbon, Vacuum. 126 (2016) 101-105.

[21] A. Nakao, M. Iwaki, Y. Yokoyama, Potassium ion implantation into glassy carbon, Nucl. Instruments Methods Phys. Res. Sect. B Beam Interact. with Mater. Atoms. 206 (2003) 211214.

[22] S. Nakao, K. Saitoh, M. Ikeyama, H. Niwa, S. Tanemura, Y. Miyagawa, S. Miyagawa, P. Jin, T. Bell, L.. Wielunski, M.. Swain, Microindentation measurements of glassy carbon implanted with high-energy titanium ions, Surf. Coatings Technol. 103-104 (1998) 384-388.

[23] A. Hoffman, H. Geller, I. Gouzman, C. Cytermann, R. Brener, M. Kenny, Formation of carbon nitride films by high-energy nitrogen ion implantation into glassy carbon, Surf. Coatings Technol. 68-69 (1994) 616-620.

[24] T.T. Hlatshwayo, L.D. Sebitla, E.G. Njoroge, M. Mlambo, J.B. Malherbe, Annealing effects on the migration of ion-implanted cadmium in glassy carbon, Nucl. Inst. Methods Phys. Res. B. 395 (2017) 34-38.

[25] B.S. Elman, M.S. Dresselhaus, G. Dresselhaus, E.W. Maby, H. Mazurek, Raman scattering from ion-implanted graphite, Phys. Rev. B. 24 (1981) 1027-1034.

[26] M. Iwaki, K. Takahashi, Wear property and structure of nitrogen implanted glassy carbon, J. Mater. Res. 5 (1990) 2562-2566.

[27] O.S. Odutemowo, Investigating effects of fission product bombarment on glassy carbon, 2017. 
[28] O.S. Odutemowo, J.B. Malherbe, L. Prinsloo, D.F. Langa, E. Wendler, High temperature annealing studies of strontium ion implanted glassy carbon, Nucl. Instruments Methods Phys. Res. Sect. B Beam Interact. with Mater. Atoms. 371 (2016) 332-335.

[29] F. Tuinstra, J.L. Koenig, Raman Spectrum of Graphite, J. Chem. Phys. 53 (1970) 1126-1130.

[30] A.C. Ferrari, J. Robertson, Interpretation of Raman spectra of disordered and amorphous carbon, Phys. Rev. B. 61 (2000) 14095-14107.

[31] Z. Ni, Y. Wang, T. Yu, Z. Shen, Raman Spectroscopy and Imaging of Graphene, Nano Res. 1 (2008) 273-291.

[32] S. Prawer, F. Ninio, I. Blanchonette, Raman spectroscopic Investigation of of ion-beamirradiated glassy carbon, J. Appl. Phys. 68 (1990) 2361-2366.

[33] J.F. Ziegler, M.D. Ziegler, J.P. Biersack, SRIM - The stopping and range of ions in matter (2010), Nucl. Instruments Methods Phys. Res. Sect. B Beam Interact. with Mater. Atoms. 268 (2010) 1818-1823.

[34] JB Malherbe, P.A. Selyshchev, O.S. Odutemowo, C.C. Theron, E.G. Njoroge, D.F. Langa, T.T. Hlatshwayo, Diffusion of a mono-energetic implanted species with a Gaussian profile, Nucl. Instruments Methods Phys. Res. Sect. B-Beam Interact. with Mater. Atoms. (2017).

Figures

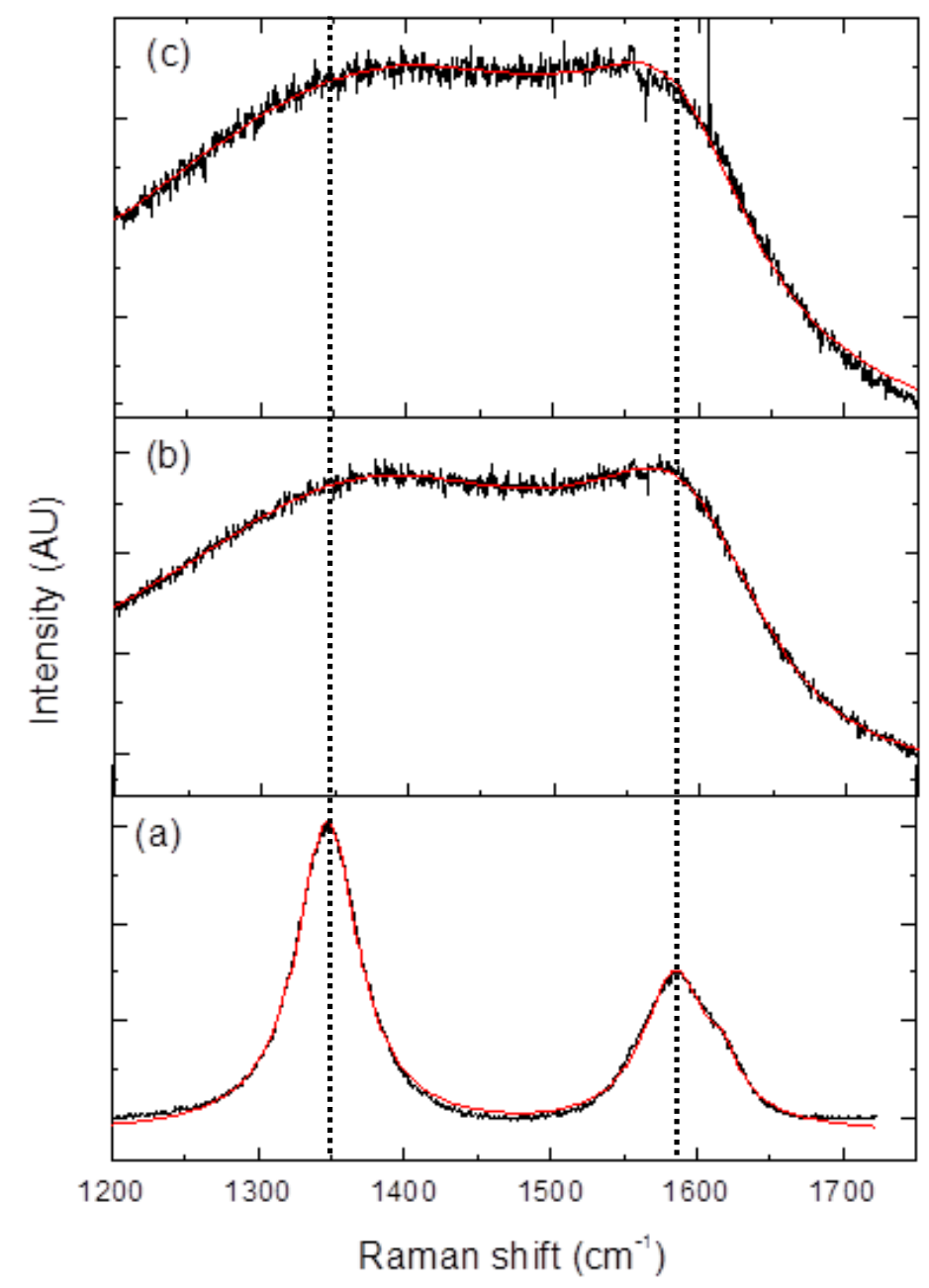


Figure 1: Raman spectra of (a) pristine glassy carbon, (b) indium implanted glassy carbon at room temperature (RT) and (c) at $350{ }^{\circ} \mathrm{C}$. Raman spectra have fitted with a combination of Lorentzian line (D peak) and a BWF line (G peak). The experimental spectrum is the black continuous line and the overall fit is depicted with the red line. 


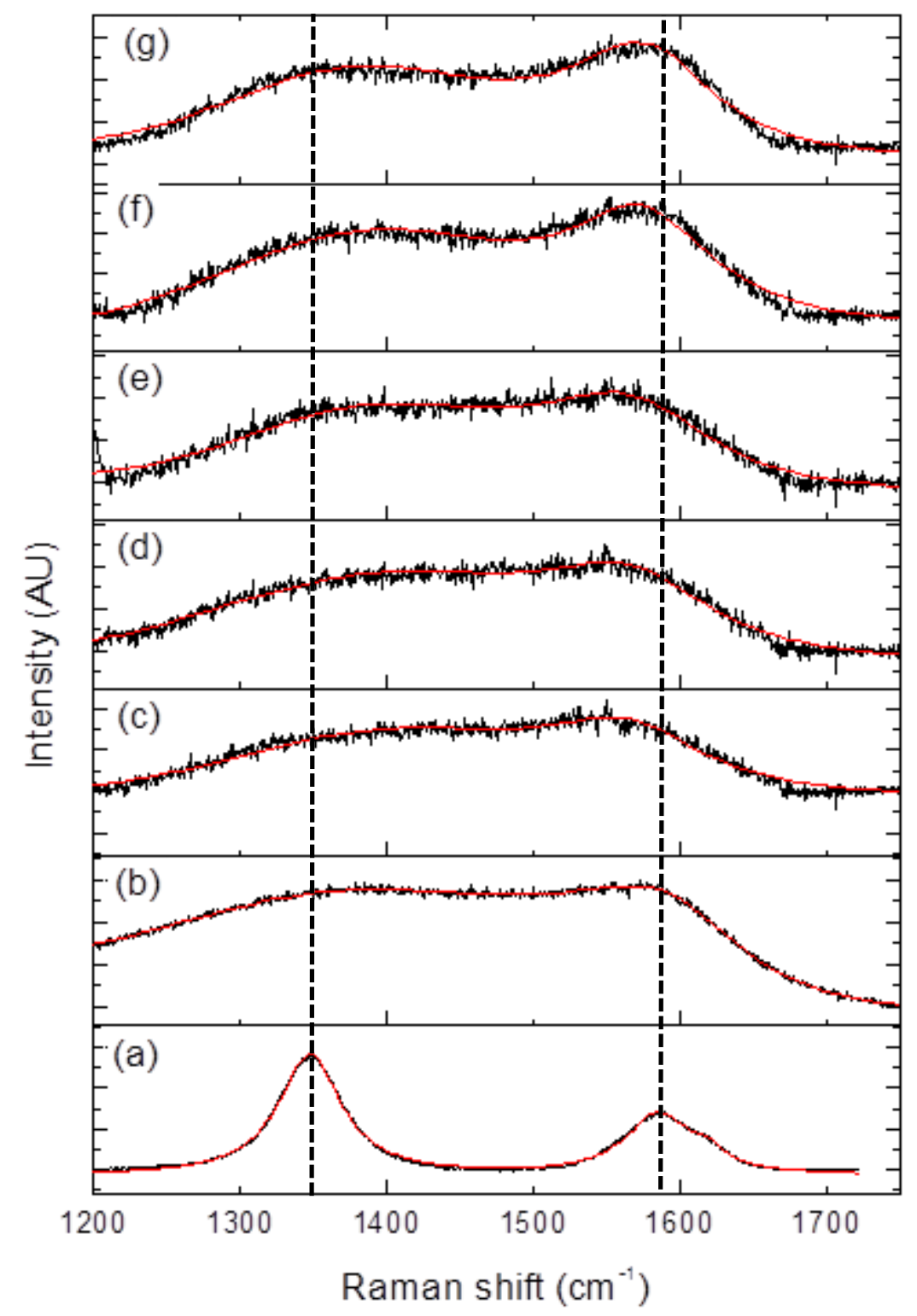

Figure 2: Raman spectra of (a) pristine glassy carbon, (b) after $360 \mathrm{keV}$ In ion implantation, after annealing at (c) $200{ }^{\circ} \mathrm{C}$, (d) $300{ }^{\circ} \mathrm{C}$, (e) $400{ }^{\circ} \mathrm{C}$ (f) $600{ }^{\circ} \mathrm{C}$ and (g) $1000{ }^{\circ} \mathrm{C}$. 


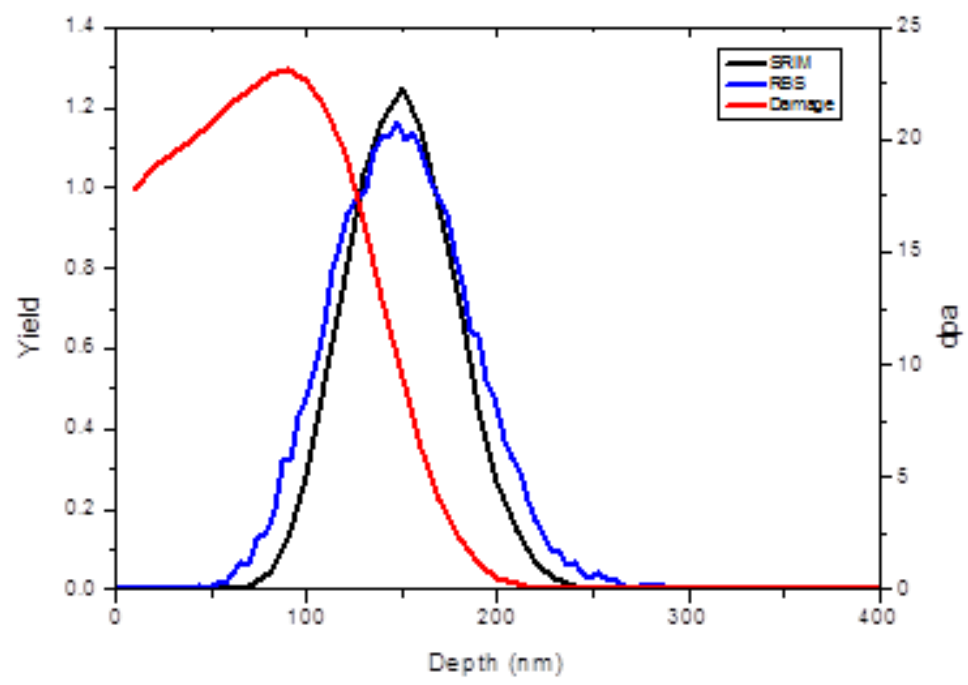

Figure 3: Depth profile of In implanted in glassy carbon at room temperature, the simulated profile and damage in dpa from SRIM 2013.

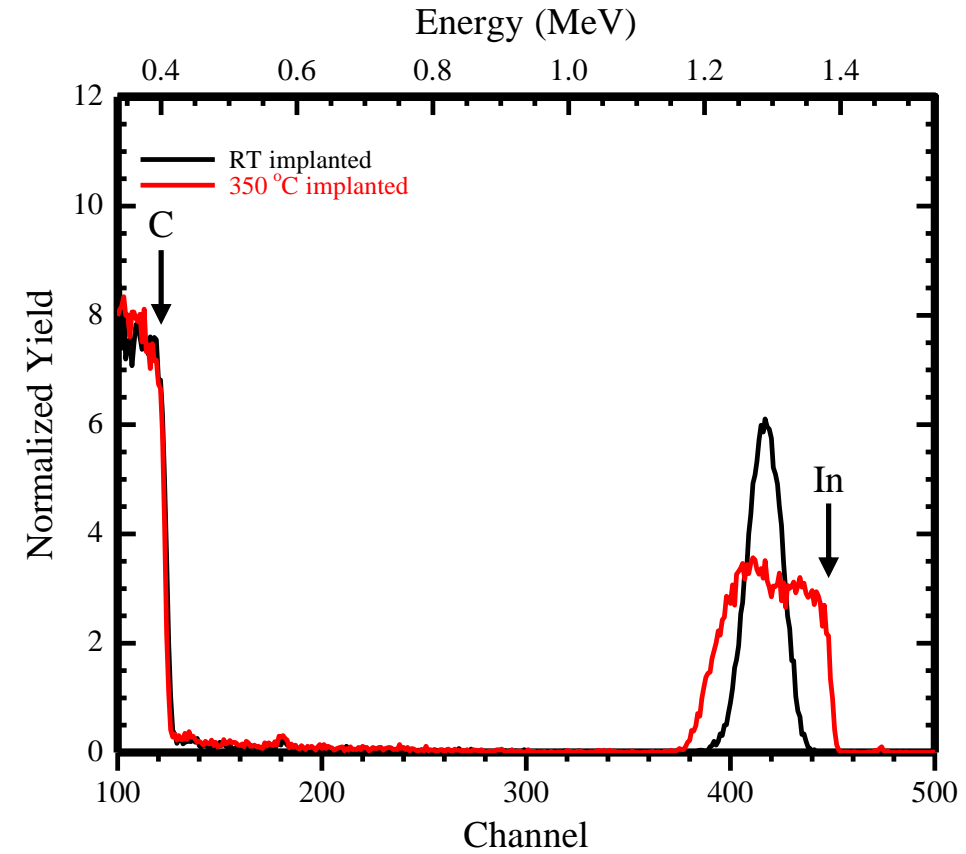

Figure 4: RBS spectra of indium implanted in GC at room temperature (RT) and at $350{ }^{\circ} \mathrm{C}$. 


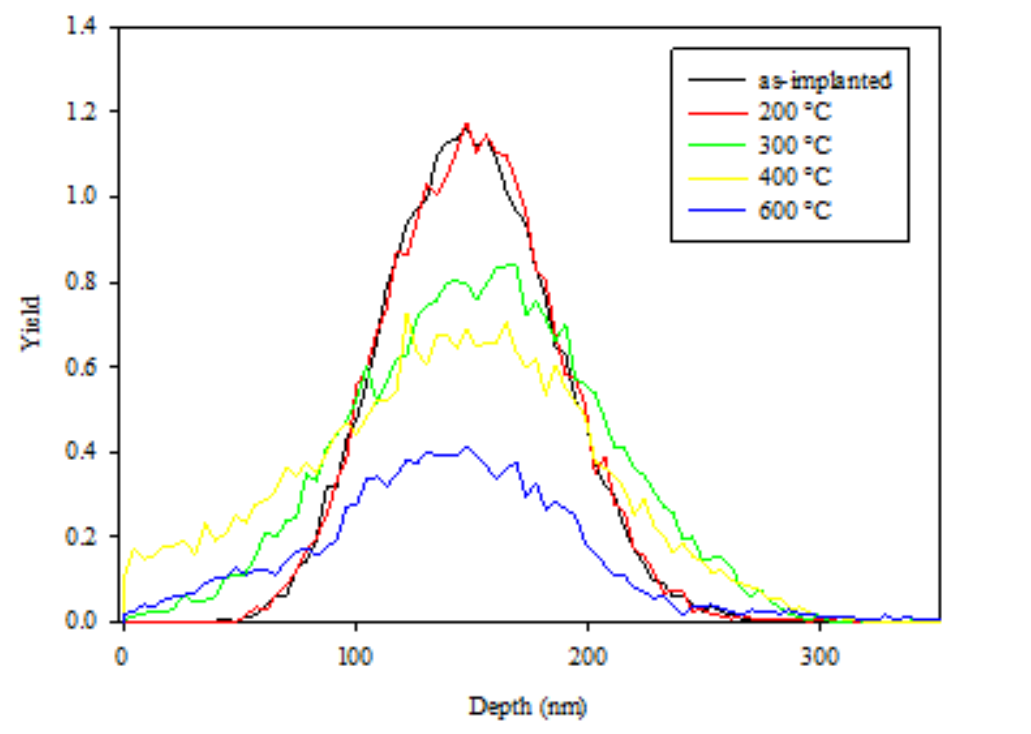

Figure 5: Depth profiles of GC implanted with In at room temperature and annealed at 200, 300, 400 and $600{ }^{\circ} \mathrm{C}$ for $1 \mathrm{~h}$ compared to as-implanted depth profile.

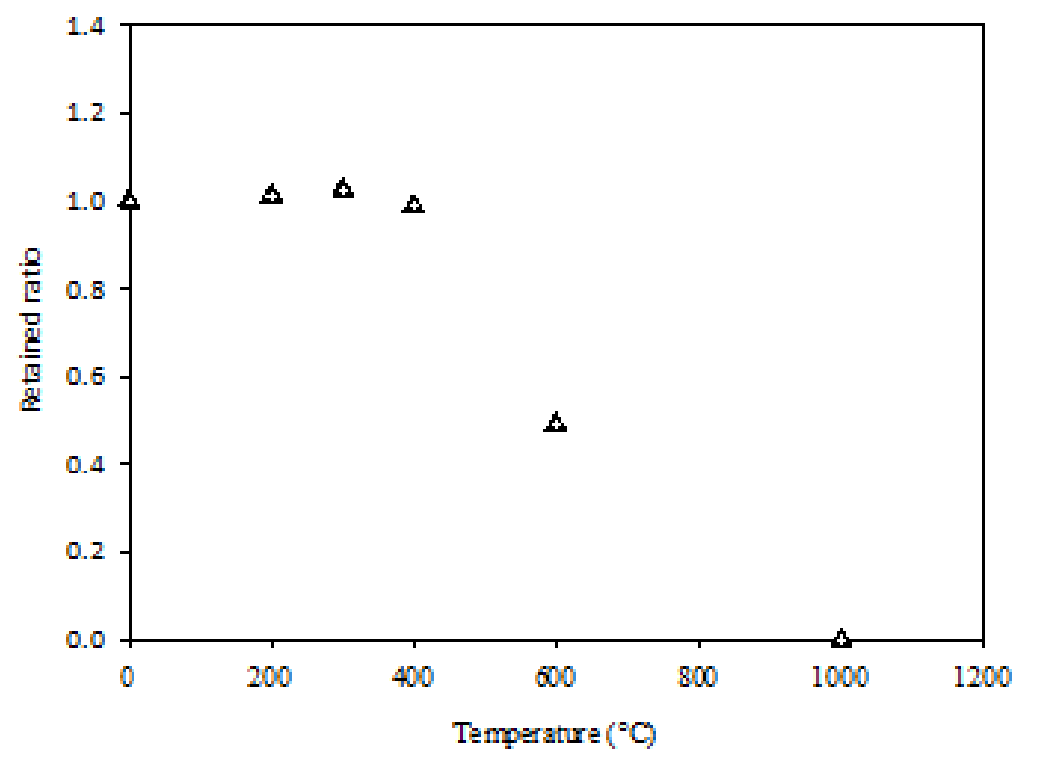

Figure 6: Comparison of the amount of indium retained within the GC substrate after annealing to that of as-implanted. 


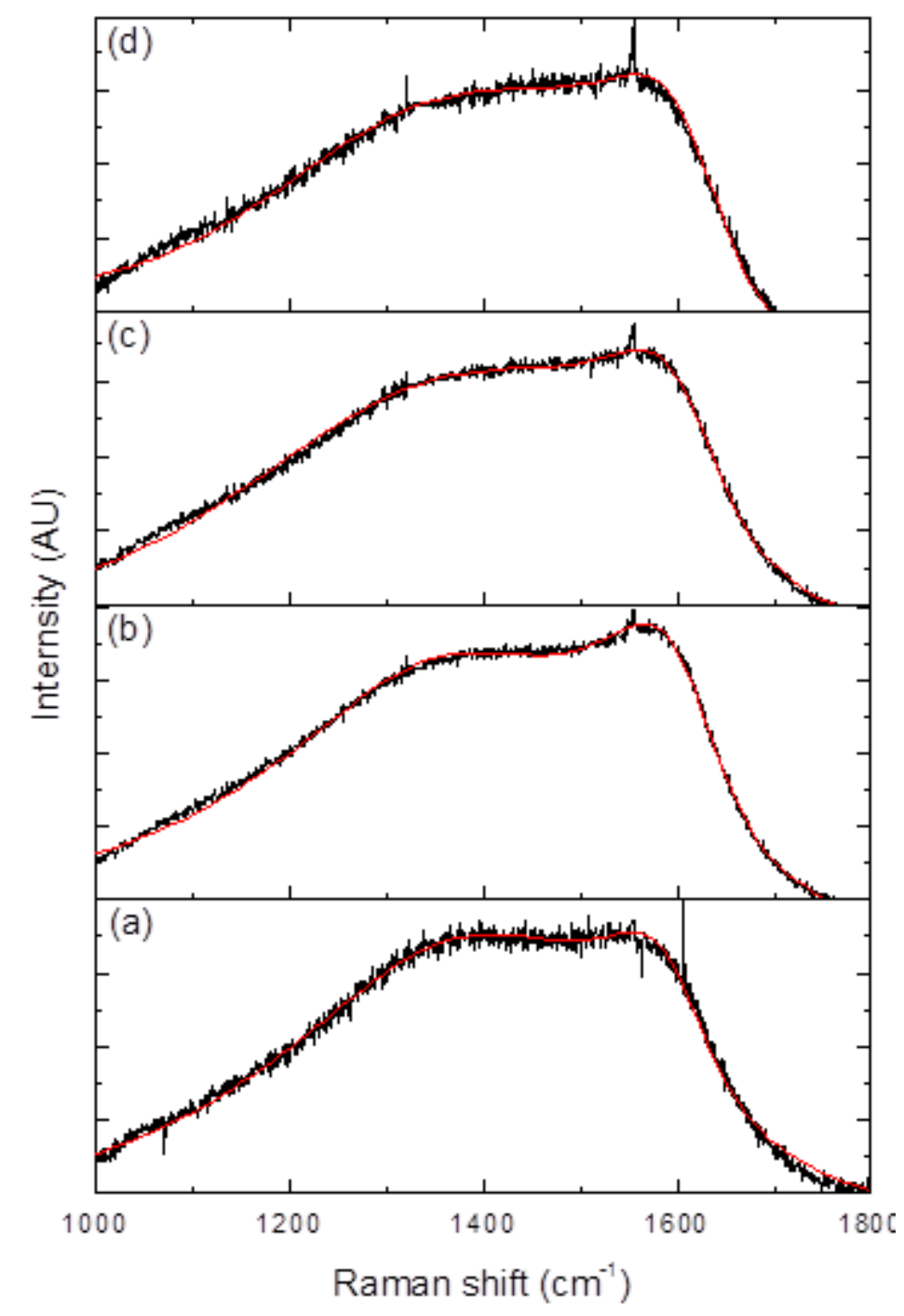

Figure 7: Raman spectra of indium implanted in $\mathrm{GC}$ at (a) $350{ }^{\circ} \mathrm{C}$ and thereafter irradiated by 167 $\mathrm{MeV} \mathrm{Xe}$ ions at fluences of (b) $5 \times 10^{12}$, (c) $1 \times 10^{14}$ and (d) $5 \times 10^{14} \mathrm{ions} / \mathrm{cm}^{2}$. 


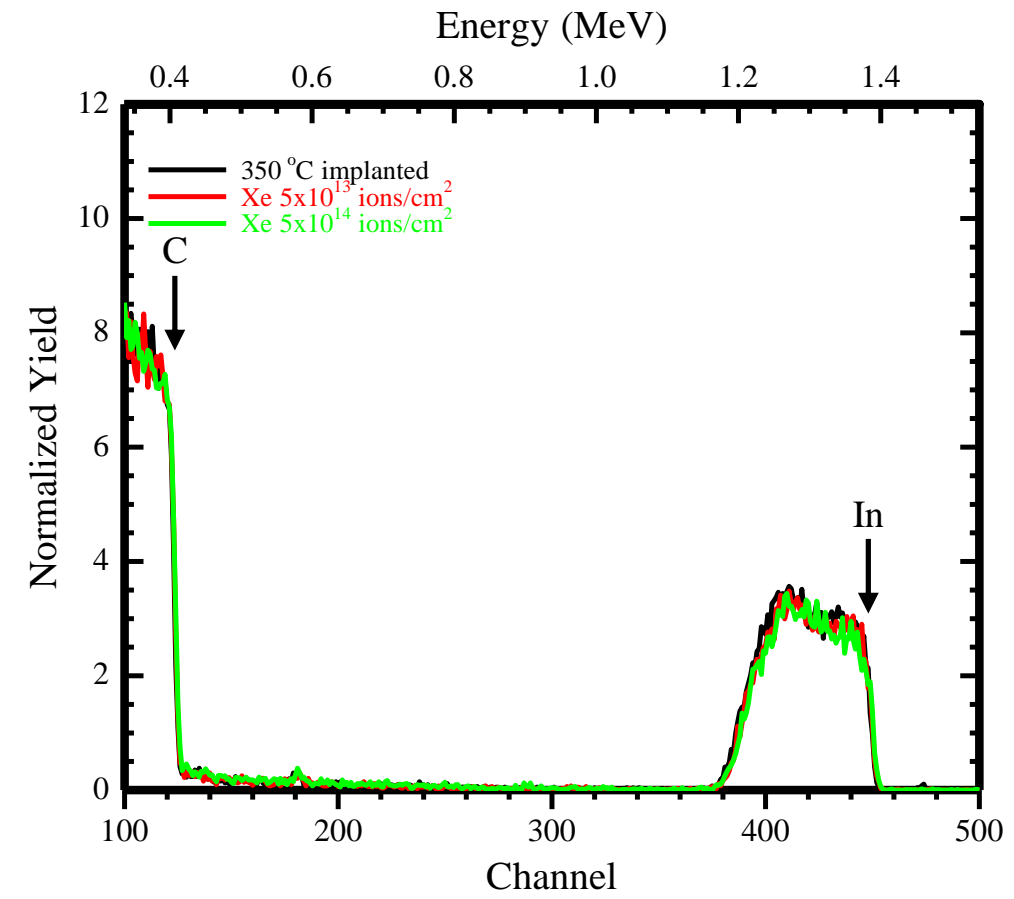

Figure 8: RBS spectra of indium implanted in $\mathrm{GC}$ at $350{ }^{\circ} \mathrm{C}$ and irradiated by $167 \mathrm{MeV}$ Xe ions at fluences of $5 \times 10^{13}$ and $5 \times 10^{14} \mathrm{ions} / \mathrm{cm}^{2}$. 